\title{
RAFUE UAI: UNA REVISIÓN BIBLIOGRÁFICA EN LA TRADICIÓN MÚRUI- MUINA
}

\author{
Juan Andrés Osorio \\ Universidad de Antioquia (Colombia) \\ chiminango@gmail.com \\ Recibido: 17/02/2019 - Aprobado: 21/07/2019 \\ DOI: doi.org/10.17533/udea.lyl.n76a10
}

\begin{abstract}
Resumen: Los saberes originarios de los múrui-muina se han practicado y transmitido por generaciones a través de la oralidad, — cantos, relatos de origen y ceremonias de la palabra con danzas - así como en una multiplicidad de elaboraciones culturales denominadas como rafue. Así pues, la propuesta del artículo consiste en hacer una revisión del concepto rafue en la tradición literaria múrui-muina.
\end{abstract}

Palabras Clave: poesía minika; rafue; múrui-muina; uitotos; lenguas indígenas.

\section{RAFUE UAI: A BIBLIOGRAPHIC REVIEW IN THE MURUI-MUINA TRADITION}

Abstract: The ancestral wisdom of the Murui-Muina people have been practiced and transmitted from generation to generation through the orality -chants, mythological narrations, and rituals of the word with dancings- and in multiple cultural practices named as rafue. So, this article proposes a revision of the concept rafue in the literary tradition of the Murui-Muina people.

Key words: Minika poetry; rafue; Murui-Muina; Witotos; indigenous languages.

\section{RAFUE UAI: KAI DIBENEDO RAFUE UAI, KAF NAIRAłMO MÚRUI-MUINA}

Due Jiza: Múrui-muina onoinafuiyai nana jiyakimona, fłnokana iemo yofuekana, nagakimado fia uaido, ruaniaimo, jiyakimona bite uaiyainiaimo, zaiyaniaimo, rafueniaimo, ua nana, ie mameki rafue. Ie jirai rafuedino komekitikai ua nana kirigaiaimo, múrui-muinainiaimo.

Eiki: kirigai; rafue; múrui-muina; uitotos; kai uaido nairai. 


\section{Introducción}

$\mathbf{J}$ unto a los ríos Igaraparaná (Kotue iye), Caquetá (Uriyanamani) y Putumayo (Kudumani) los múrui-muina han sabido conservar su cultura gracias a sus modos de pensar, de ver, sentir y nombrar el mundo. Una de las elaboraciones culturales de la tradición múrui-muina es el rafue. Así pues, en este trabajo se propone hacer una revisión bibliográfica de este concepto, valioso para los estudios literarios.

La lengua minika es una de las familias que, junto al bue, el mika y el nipode, hacen parte integra de la tradición múrui-muina. Si la lengua minika significa literalmente «¿qué es?», pensar sus formas de nombrar las cosas y el mundo es explorar cada una de las manifestaciones del sentir y del pensar propios de esta cultura. Así encontramos en el Kaì komuiya úaiyai jiyaki jágaí, de Juan Kuiru Naforo, que estas lenguas han nacido en el deslumbramiento, en el asombro, en la indagación y en la capacidad de reconocer el origen, una propia historia serpenteante.

Reflexionar sobre los conceptos de la lengua minika hace fácil el acceso a los modos de elaborar sus conocimientos, recogidos en canastas que se denominan kirigaitat ${ }^{1}$, en donde están guardados los saberes ancestrales que han sido tejidos a lo largo de la existencia. Estos conocimientos, tan antiguos como la misma cultura, han sido transmitidos en una extensa fila de generaciones que se remite a los orígenes. Por eso, pensar las palabras que fundan la cultura recuerdan que las mismas han sido tejidas en participación con todos los seres que rodean su hábitat y, con razón, pensar estas palabras desde sus producciones orales y escritas permiten reconocer la importancia que tiene en la literatura múrui-muina el territorio, las sociedades bosquesinas ${ }^{2}$ que la conforman, sus prácticas rituales y pedagógicas y los trabajos manuales que les proveen el buen vivir. No es en vano que los mapas del territorio estén grabados en las historias

1. El canasto de pensamiento ancestral (kirigai) que se ha pensado por sus sabedores como «hilo y aliento de los ancestros», ofrece la posibilidad de ver cómo el pensamiento minika es un tejido en el que cada concepto es parte integra del lenguaje tejido desde el origen. Se sugiere ver el excelente trabajo de Vivas titulado Kirigaiai: Los géneros poéticos.

2. Jorge Gasché realizó un gran estudio de las comunidades amazónicas y del territorio. Bosquesinos son aquellos que viven en el bosque y del bosque y de sus aguas. A diferencia del campesino, el bosquesino «practica la horticultura, o, para usar un término corriente en la antropología, el cultivo de corte y quema o roza y quema» (Gasché, 2012, p. 22). En sus prácticas de siembra se le da un tratamiento diferente a cada tipo de planta, siembra en policultivo y tienen un ciclo de renovación de los bosques. 
de la tradición, en los jagagiai ${ }^{3}$ se cuenta cómo se originó el mundo, la humanidad, el lenguaje, los ríos, los árboles, las plantas, los animales y cada uno de los seres que pueblan la selva (Kuiru, 2017; Vivas, 2015).

De igual manera, la lengua minika ha colaborado para que la sabiduría de otras lenguas similares como el bue, el nipode, el nonuya y el mika perviva en las palabras de sus narraciones y en sus cantos, y así se reconozca la memoria de lo humano, de la selva, de las plantas, de los ríos, de los utensilios, de los alimentos, etc. Sin embargo, debido al genocidio cometido por la Casa Arana a principios del siglo XX contra los pueblos amazónicos, las familias dialectales como el nonuya o el okaina, entre otras, terminan por adoptar la lengua de los grupos con más hablantes como el minika, el portugués o el español. Esto, obviamente, brindaba beneficios de sobrevivencia, pues las alianzas se realizaban no sólo entre los individuos o los pequeños grupos sobrevivientes, sino entre las lenguas que custodiaban entre sí los saberes de sus respectivas tradiciones. Justamente, como se verá, el rafue provoca un encuentro con la palabra ritual entre la cultura múrui-muina y otras tradiciones que se reúnen para compartir sus saberes, sus historias de origen, sus cantos y sus danzas.

\section{Rafue: Una palabra que amanece}

Si bien rafue, en efecto, puede traducirse por palabra, no se refiere a una «palabra cualquiera», es decir, no una palabra usada sin fuerza, sin intención y sin propósito. Todo lo contrario, el rafue es una palabra plena de poder creativo, la que dicha en boca de los abuelos sabedores llega a materializarse en acciones que benefician a la comunidad. El plural de la palabra rafue, rafuentai, da indicios de que se trata de un conjunto de saberes que son un legado cultural milenario. Los rafueniai son elaboraciones culturales de una gran factura poética. Así, el rafue puede manifestarse en diversos géneros poéticos, en forma de jira (rezo), de rua (canto), yetarafue (consejo) o jagai (relato de origen), ente otros. Estas formas poéticas, por la capacidad de compendiar un gran acervo de legados ancestrales, solo pueden morar en un recipiente igualmente poderoso, en los kirigatai (las canastas de pensamiento), «este término

3. El jagagi es uno de los géneros poéticos centrales de la cultura minika. Funciona como hilo (igai) que teje los distintos géneros del pensamiento. El jagagi narra las historias que dan origen a la cultura y les dan comprensión a las comunidades de su propio territorio y de su clan en particular. 
enuncia, al mismo tiempo, las diferentes formas expresivas en las que se muestran sus prácticas rituales y sus saberes ancestrales. En una palabra, sus formas de sentir y de inventar el mundo» (Vivas, 2012, p. 226). Estas que a su vez tienen «el poder de organizar y transmitir experiencias derivadas de la auscultación del mundo» (Vivas, 2012, p. 227) y les permite ser actualizadas dentro un ámbito ceremonial en la anáneko, la casa de pensamiento ancestral del pueblo minika, donde se comparten los saberes culturales milenarios que se renuevan justamente para direccionar las decisiones de las comunidades.

Los kirigatai son los contenedores de los saberes que se han legado ancestralmente y los cuales son actualizados a través de las historias, los cantos y los saberes milenarios que se recogen y se transmiten oralmente. Estos recipientes guardan los códigos arcanos de una cultura indígena que le canta a la selva y a los saberes ancestrales otorgados por ella. El rafue hace referencia a un recipiente que puede ser la boca (fue) o la que contiene las cosas de poder (raa). El kirigai impresiona tanto como la boca por las cosas poderosas que se guardan en él. La boca que canta pone en acción la fuerza de la palabra sorprende con su sonoridad, con su música y con su poesía, pero va más allá de la mera enunciación, pues libera un poder que se instala entre las cosas, se vuelve una cosa entre las otras y transforma las cosas que nombra. Una mera traducción literal de rafue dificulta la comprensión que encierra su sentido profundo: «Si raa $=$ cosa de poder; y fue = boca, una traducción inmediata es palabra; pero no cualquier palabra sino aquella plena de fuerza, creadora, orientadora y correctora, la que puesta en boca de los dioses hace amanecer» (Urbina, 2010, p. 106).

La palabra de poder (rafue) se distingue de la palabra uai, el significante de la palabra de uso cotidiano, por la capacidad creativa, formadora, correctora y, finalmente, por la fuerza que quiere hacer amanecer (monaitaiakade). Dar claridad, amanecer (monaide) en lengua minika se refiere a aquello que deslumbra en el horizonte, el día (mona), el cielo (mona), pero también «amanecer en el pensamiento minika se refiere a emerger de las capas más profundas a las capas más externas. Amanecer es hacerse visible en un momento dado, pues antes estaba oculto, sumergido bajo esta capa de la tierra» (Fairinama, 2016:32). El amanecer (monaide) permite ver aquello que estaba inmerso en la profundidad de la tierra o en la oscuridad de la noche, por esa razón el 
rafue se ausculta durante noches enteras, cuando todos duermen. Así lo advirtió Pedro, el intérprete de Preuss:

Amoïjedi atomona kegaza kaijedi naiona yoga / ieri uuñoñede urutikodì intoideza / ieri kakañedikai kaidi / ieri daje eeimiemo ite naikidoni bakakidi / atomonade maijiaide niade / ieri yooireiniga atomona naiona yoyena maijireinina (Preuss, 1994, p. 680).

Las tradiciones de ustedes se escriben de día, mientras que las nuestras se cuentan durante la noche. Por esta razón, nuestros niños no las aprenden, ya que están durmiendo y nosotros tampoco las escuchamos. Las enseñanzas y las tradiciones solamente las poseen los hombres mayores. De día la gente trabaja; no se cuenta nada para poder hablar durante la noche, cuando nadie trabaja (Preuss, 1994, p. 681).

Las tradiciones poéticas milenarias de estas culturas se cuentan y luego se danzan en la celebración del rafue en las noches hasta el amanecer, lo que las deja pletóricas de conocimiento, de salud y de la fortaleza necesaria para continuar trabajando durante el día. Estas culturas que amanecen en el rafue, celebrando la vida con las palabras poéticas son culturas del amanecer, procedentes ancestralmente del Monaiya Namani (el río Amazonas,), el río en el que amanecen todos los ríos (Monaiya: «amanecer» y Namani: «río de todos los ríos»). Este último río que ha proveído milenariamente a innumerables naciones indígenas, proviene justamente del tronco del Moniya Amena (el árbol de la abundancia), y despliega un enorme potencial energético y vital a través de sus innumerables afluentes. De ahí la profunda relación entre el Monaiya (amanecer) y la Moniya (abundancia). El Moniya amena es, de hecho, uno de los relatos cosmogónicos más conocidos en la literatura múrui-muina, ya que a partir de esa narración arborescente se puede comprender el entramado fluvial de la selva húmeda tropical y, al mismo tiempo, la convergencia rizomática de estas tradiciones con sus territorios de origen.

Monaitaiakade es una expresión poética que habla de la concreción en obras del pensamiento. La raíz mona- se refiere a la claridad del día, de la luz e incluso de una palabra, mientras que el sufijo - aka se refiere a la voluntad que participa en la acción. Por ello, hacer amanecer la palabra es efecto de la voluntad de hacerla amanecer, ya que la acción tiene toda la fuerza del pensamiento y del corazón. A través de la expresión rafue monaitaiga (hacer amanecer la palabra) la comunidad reconoce verdaderamente lo uafue (las cosas que se comunicaron), sea a través de los relatos de origen (jagagiai), de los cantos (ruaniai) o de las palabras de consejo (yetárafueniai). ¿Cómo se prueba que la palabra dicha es una palabra de hacer amanecer? La palabra amanece cuando se 
constata que lo proyectado es ya un hecho, es decir, cuando se hacen visibles las obras y los frutos del trabajo, y de esta manera se prueba la buena palabra:

Nïi ñuera úai

ja ua monaide. jmm

Akie izoide. Jmm

Aki dinona mei bai

fia afe úai

mei ja baie ua ñuéfuena fakade, jmm jmm

fia uaina ja. jmm

Aki dinori ari ua ja mei monaide, $j m m$

ja kiona. jmm jmm (Candre/ Echeverri, 2008, p. 38).

Esa misma buena palabra

ya—en verdad - amaneció.

Así es.

De aquí en adelante

sólo esa conversación,

pues ya se probó como buena Palabra

— sólo de palabra. Hasta aquí

ya se amaneció,

ya se vió (Candre/ Echeverri, 2008, p. 41).

Y, sobre todo, la palabra amanece cuando procede desde lo más profundo del corazón, aun si está triste, y cuando el pueblo celebra el rafue cantando alegremente se anima el corazón, se le van las penas, se aclara el horizonte y amanece un nuevo día para la comunidad, porque el rafue es la palabra de la tribu (nairai) y el canto es el que hace amanecer (monaide), por lo que se amanece cantando:

$J i$

Meita nairai ruari meita monaide.

Ie uruki ni eia komekido

jaka kaimarerie rotiaioi iadi

Jmm (Fairinama, 2016, p. 128).

Ji.

Así la tribu cantando hizo amanecer.

Su pueblo con corazón lloroso,

aunque siempre contento, cantó.

$\mathrm{Jmm}$, aunque (Fairinama, 2016, p. 129).

El rafue es la palabra con que reflexiona y canta la cultura minika, la cual se comunica en las ceremonias de la palabra, armoniza la comunidad, les da palabras de fortaleza a los seres humanos y los orienta en su diario vivir. El rafue es la palabra poética de la lengua mintika. Viene de lo hondo del tiempo y atraviesa la selva como el manguaré. Se mueve desde el origen, vibra, se escucha, se le atiende desde la 
antigüedad. El pensamiento minika se nos muestra pleno de fuerza, vigor y dulzura en los cantos y las narraciones de su poesía. Rafue es, ciertamente, una clave para comprender el pensamiento ancestral, con esta palabra plena de sentido estético hacemos referencia a las palabras dichas desde la ancestralidad que orientan el presente de los hombres a través de la buena palabra (ñuera uai) y la palabra dulce (naimerede uai). Los saberes milenarios, los cuales hablan de los acontecimientos más importantes, son los más dignos de ser escuchados, aprendidos y legados a las nuevas generaciones. Las palabras que se denominan rafueniai son poderosas ante todo porque ellas tienen la potencia de hacer amanecer (monaitaiakade) cosas verdaderas, es decir, son palabras pletóricas de energía creativa, que fundan y vigorizan a las comunidades, que les ayudan a preservar la memoria ancestral y otorgan el poder de transformar, sanar, aconsejar, orientar, enseñar, entre otros atributos, a diferencia de la palabra vacía (taino uai), las palabras que no amanecen en obras o que no corresponden con lo que se vive; De este modo, el aliento de vida (jágïiyi) de la lengua minika sugiere escuchar en el rafue una palabra que trae saberes milenarios.

El rafue es la piedra angular de la lengua minika. La palabra rafue hay que desentramarla poco a poco, como si se tratara de un canasto al que hubiera que destejer cuidadosamente para conocer su trama. El investigador Juan Álvaro Echeverri aseguró que el rafue no es una cosa, ni siquiera una palabra. Tampoco se trata de una forma literaria, de un estilo o de un canon:

Rafue no se refiere de hecho ni a una «palabra» ni a una «cosa», es la actividad mediante la cual las palabras se transforman en cosas — es el movimiento de lo deseado a lo real a través del tiempo- Este movimiento está sintetizado en las dos raíces que forman el vocablo rafue: raa «una cosa» e ifue «algo que se dice». Cuando la actividad de rafue apenas comienza, se manifiesta como «Palabra» una palabra que nombra lo que busca, una palabra con «poder»; hacia el final de la actividad, rafue se manifiesta como «cosas» — comida, cacería, criaturas, etc.-, lo que se buscaba (Echeverri, 1993, p. 63).

Este proceso de dilucidar el término rafue, apartados de lo meramente formal, de su sentido literal, permite observar, en principio, que el rafue no es la mera «palabra» o la mera «cosa pronunciada», sino que es un movimiento transformativo en el que se concreta aquello que se desea. Echeverri da cuenta de cómo la palabra rafue sintetiza un pensamiento ancestral que investiga la manera de resolver situaciones reales de la comunidad a través del poder de las palabras. Este movimiento del pensar minika se desarrolla en dos momentos: inicialmente, cuando la palabra de «poder» se pronuncia, 
cuando se comunica y se reflexiona a la tribu (nairai); y en un segundo momento, cuando la palabra amanece gracias al trabajo, a la práctica, a la voluntad que la hace amanecer (monaitaiakade). Este ritual donde se transmite la palabra ancestral es un espacio de pensamiento en el que los saberes que transmiten los abuelos y sabedores se comparten con el ánimo de pensar los temas comunitarios, territoriales y cosmogónicos que se requieren ordenar o poner en equilibrio. Esta palabra que expone las narraciones milenarias no quiere quedarse en la banalidad de la enumeración de acontecimientos pasados, sino que busca la armonía y la solución de los conflictos naturales y humanos. En suma, aspira a corregir los malestares culturales a través de las palabras de «hacer amanecer». El fin del rafue es el buen vivir de los seres humanos y la naturaleza misma, ya que todos los seres están sabiamente tejidos (kominitaiyi) con la madre tierra, en donde todas las criaturas (komini) hacen parte del mismo tejido (niya).

\section{El rafue en las palabras del origen}

Fernando Urbina Rangel se ha distinguido por hacer un gran compendio de las historias de origen de los múrui-muina al recoger canastos de conocimiento (kirigatai) aprendidos en la anáneko por largo tiempo. Además, ha compilado una antología de jagagiai, bajo el título Las palabras del origen, en la cual recoge algunas narraciones de los abuelos que permite reivindicar sus saberes, enriquecer el diálogo con estas culturas y dar a conocer una maravillosa muestra poética de sus relatos de origen. Los rafuentai son las palabras ceremoniales que compendian el saber ancestral a partir del cual los abuelos aconsejan a su gente. Los mismos abuelos se sientan en rituales de la palabra, donde con la dulzura de las plantas del tabaco y de la coca transmiten los conocimientos ancestrales: «Para ellos, el saber estriba fundamentalmente en la palabra. Saber es saber las palabras. Conocer con profundidad es recordar lo dicho alguna vez en el mambeadero, donde el abuelo sentado en el banco ritual, se constituye en el ordenador» (Urbina, 2005, p. 86).

El rafue rememora el tiempo de la creación. La lengua minika recrea con los jagagiai el origen de los tiempos y recuerda en sus historias de origen las enseñanzas de los ancestros. El rafue recuerda el tiempo en que los hombres se comunicaban sentados junto al fuego, es el rafue el que nos invita a realizar una peregrinación hacia el lugar de 
la escucha, allí donde se tejen las primeras palabras, un origen que habla en las lenguas del amanecer. En el rafue se manifiestan los saberes milenarios de la cultura minikka, el lugar de encuentro de la poesía y los hombres no es aquí el poema sino la anáneko, la casa de pensamiento ancestral de los minika, «ícono que simboliza el universo y la historia, síntesis de lo espacial y lo temporal, morada y memoria. Dentro de ese vientre materno el hombre biológico se construye como ser cultural mediante la socialización. Allí tendrán los rituales» (Urbina, 2010, p. 39). Las palabras poéticas, los cantos, las danzas, los relatos de origen, etc. se escuchan en este espacio de conocimiento. Así, la palabra abre la posibilidad de pensar todas las dimensiones culturales, las actividades cotidianas y las prácticas rituales, en momentos especiales donde se escucha la palabra en una atmosfera de atención y concentración, generada por el uso de las plantas de poder, la coca y el tabaco. Las palabras pronunciadas por el rafuenaama ${ }^{4}$ son escuchadas por los que concurren a estos «círculos de palabra». El rafuenaama es el sabedor que se encarga de transmitir y ordenar el conocimiento, es aquel que tiene en su canasto de sabiduría (kirigai) las lecciones que ha recogido durante toda su vida, legadas por sus ancestros, aprendidas en la chagra junto a las plantas del conocimiento y en los círculos de mambeo, donde se reúnen a escuchar las palabras en compañía de las plantas de coca y de tabaco.

Eudocio Becerra Bigidima en El poder la palabra señaló la necesidad que tienen las culturas indígenas de reconocer los conceptos fundacionales de sus lenguas nativas, toda vez que se quiera hacer un acercamiento a su pensamiento, ya que «el concepto de lenguaje, de palabra está por lo general muy centrado en nociones de teóricos europeos o de tradición occidental» (Becerra 1998, p. 15); pero este llamado es, a la vez, una valiosa oportunidad de contribuir con los estudios lingüísticos y literarios de las naciones originarias del Abya Yala. De esta manera, Eudocio Becerra presentó su concepción del lenguaje:

Aquí se nos cuenta que la palabra nos viene de moo (el padre creador) y que tiene, además, un lugar de procedencia, «la morada del gran Nimaira Buinaima, la maloka sagrada $»^{5}$. La lengua está resguardada en una casa primigenia, un espacio donde se elaboran los conocimientos más especializados de la cultura, la anáneko, la universidad de saberes

4. Rafuenaama: literalmente «dueño de las palabras», es el abuelo que por su sabiduría está encargado de que las ceremonias de la palabra se realicen en armonía y bienestar.

5. Se prefiere el termino anáneko al de maloca, ya que esta palabra es un agregado portugués utlizado por los conquistadores que significa «caza de indios». Según el DRAE, es un vocablo proveniente del mapuche malocán, el cual hace referencia a las viviendas de los indígenas. 
ancestrales de los pueblos amazónicos. En el origen, la palabra proviene de los dioses. La mención a moo, el padre creador, en realidad nos está diciendo que la palabra desde el origen contempla un gran poder, nada menos que el poder dar la vida e, incluso, de quitarla. La palabra de poder que estaba en boca de moo se humaniza, el poder hacer cosas a partir de las palabras, de ahí que «ella, esta palabra, es poseedora de acción; ejecuta acciones simbólicas como matar, quemar, castigar, maldecir, curar, enseñar y corregir. Así se expresa la fuerza que posee la palabra» (Becerra, 1998, p. 19).

Las palabras tienen un poder pedagógico tanto como deformador, el de beneficiar como el de causar daño. Aquí se resalta el gran poder de la palabra, el más primigenio y original. El poder del rafue es poseer la más vital expresión que pueda tener el lenguaje, el poder ser un «ordenador de la realidad», es decir, el poder regular las relaciones cósmicas, naturales y humanas. La palabra de poder que es el rafue conjura la existencia, así como:

[...] limpia, ordena cada cosa en su lugar, cada cosa tiene su final su término, no es que aparezcan las cosas porque sí, las cosas aparecen porque alguien las ha ensoñado, alguien las ha querido, insinuado. Todo son insinuaciones que en un momento se realizan. El padre creador todo lo que veía lo materializaba, eso se llama monaitate (Becerra, 2003, p. 28).

Las ceremonias de la palabra tienen como fin armonizar la vida en comunidad y equilibrar las relaciones con el cosmos, el territorio, las plantas, los animales, los árboles y los ríos.

El poder que tienen los rafuentai de ordenar la realidad depende no sólo del poder que detenta el sabedor de saber hacer, sino del saber pensar con el corazón. Así, toda creación «tiene que realizarse con las fuerzas más poderosas del corazón, con las entrañas, con el aliento, el sentimiento que piensa, la voluntad, aquello que se designa con el nombre de pensamiento con corazón» (Becerra, 2003, p. 14). Sus palabras harán amanecer sólo cuando estas provengan del corazón. Tal es el peso de las palabras que los sabedores debe aprender a dietar la palabra, a corregir su propio corazón y sus deseos, ya que de sus yetárafue (palabras de consejo) van a disponer los hombres para direccionar el destino de sus comunidades, organizar sus familias y sus propios pensamientos:

Yo necesito esa palabra de poder, esa palabra fuerte será transformada en buenas palabras, palabras con que enseñaré a mis hombres. A través de mí, las palabras fuertes serán palabras de conocimiento, de tranquilidad y de fortaleza. Con esta clase de lenguaje se recibe el poder que llega del Padre a través del rayo, y estas son las palabras que reciben y necesitan los grandes sabedores (Becerra, 1998, p. 17). 
Ser rafuenaama, sabedor de las palabras de poder, es una de las mayores responsabilidades que se adquieren en vida en la cultura múrui-muina, lo cual implica tanto transmitir o enseñar conocimientos como la de aprender a escuchar. Londoño enumera las variadas formas en que los preceptores y los aprendices se reparten compromisos para la transmisión y la adquisición de los saberes: «la transmisión de conocimiento y su recepción involucran responsabilidades mutuas (una vez que se aceptara que el conocimiento se transmitiera legítimamente)»(Londoño, 2004, p. 189). Estas responsabilidades tienen que ver con el uso de las plantas de poder, con las dietas alimenticias, las moderaciones sexuales y con las dietas de palabras. Estas últimas son de gran importancia, ya que saber las palabras es conocer su impronta ética, poética y pedagógica:

Con estas palabras se enseña a niños y adultos. Estas palabras son las que dan larga vida y fuerza para trabajar. Estas palabras son como la macana. Anteriormente bajo estas palabras eran protegidos los hombres para que se multiplicaran. Anteriormente cuando se presentaban rayos y tormentas se narraba la historia y los abuelos callaban a los hombres porque en ese momento se dice que el cielo y la tierra entran en comunicación. No es fácil apoderarse de la palabra del Creador, y tampoco es fácil responderle. Por eso cuando el abuelo recibe esta energía, la absorbe en su cuerpo y luego con ella protege a todos los hombres para que vivan sanos y se multipliquen. A través del manejo de las palabras el hombre busca la protección. El uso de este lenguaje como enseñanza recibe el nombre de rafue, tradición que nos sirve para corregir a los hombres y al medio en que viven (Becerra, 1998, p. 17).

La pedagogía ancestral múrui-muina se apoya en las ceremonias de la palabra del komuiya jibibirit uai (las palabras de vida del mambeadero), pero no concluyen en este espacio pedagógico, sino que esos saberes se distribuyen por los diferentes campos del saber de la cultura, ya que tienen como fin fortalecer a los hombres y a las mujeres para que tengan una buena calidad de vida, una vida sabrosa. El rafue es la fuente de vida para las generaciones futuras, son las palabras las que alientan, fortalecen, sanan, corrigen y dan larga vida a las nuevas generaciones. Uno de los principales postulados del pensamiento múrui-muina, que Londoño retoma en su trabajo Muinane, es este propósito moral con el que viven los hombres: «el propósito último de toda Persona verdadera (es decir, todo humano, por definición dotado de moralidad), es el de lograr multiplicar de manera humana a su gente» (Londoño, 2004, p. XXIX). Aquí se habla de un proyecto pedagógico: el de humanizar la tribu a través de las komuiya uai (palabras de vida), equivalentes al cuidado que se les presta a la germinación y la siembra de las 
semillas en la chagra. La humanización es la gran tarea cultural, consistente en cuidar los procesos de crecimiento y desarrollo de sus gentes; como también se pone un cuidado especial en que los pensamientos y emociones se humanicen, es decir, sean fríos, amorosos y plenos de propósito a través de las prácticas rituales, las palabras de consejo y las prácticas alimentarias. En esta tarea cultural de germinar (komuide) son igual de importantes las palabras de poder como las plantas aliadas: diona (planta de tabaco), jíibie (planta de coca) y farekatofe (planta de yuca). Ellas son utilizadas frecuentemente por la comunidad en los mambeos para propiciar palabras dulces. Esta armonización de las plantas de poder intenta generar el buen vivir de la comunidad, en el que:

[...]se incluye la salud corporal, la fecundidad y tranquilidad de los individuos; un estado de interacción amorosa entre parientes y co-residentes; y por último, el carácter sano y propicio de las sustancias rituales, los alimentos, la tierra, las aguas y todo lo demás que rodea a la gente (Londoño, 2004, p. XXXVIII).

Este jagai (relato de origen) que comparte Eudocio Becerra recrea el encuentro original entre el lenguaje y la humanidad, un encuentro por demás poético, signado por el rayo y la tormenta. Aquí se revela el origen de la palabra en un jagaí de la lengua bue. Para el aspirante de este conocimiento ancestral, es imprescindible seguir una estricta preparación física y mental en la que se incluyen el manejo de las plantas, el conocimiento del territorio y de las palabras ceremoniales. Esta preparación (finorite) les enseña a estar atentos a las señales de la naturaleza. Por eso, «cuando brilla el rayo los abuelos sabedores reciben esta energía, y es en ese momento cuando piden al Padre Creador» (Becerra, 1998, p. 16) las palabras de poder:

kai moo uai baie jamai boriyana kiokaiya

kai moo uai baie jamai ameona kakaiya

kai moo uai baie jamai aifina riiya

la palabra de nuestro padre se divisa

solamente bajo la forma de rayo,

sólo se escucha en forma de trueno,

y tan sólo nos llega en forma de viento (Becerra, 1998, p. 16).

El rayo es símbolo de que se ha abierto un portal de comunicación donde se transmite el legado de saberes, «con esta clase de lenguaje se recibe el poder que llega del Padre a través del rayo, y estas son las palabras que reciben y necesitan los grandes sabedores»(Becerra, 1998, p. 17). El relato de Jacinto Bigidima sobre el origen del 
poder de la palabra citado anteriormente permite analizar algunos elementos que sobresalen por su simbología. En este caso el rayo es el medio de comunicación de la palabra y es la presencia misma del poder de la palabra. Así se le atisba, viniendo de lo más lejano, de lo alto, de lo invisible y cuando viene el nimairama ${ }^{6}$ ha de saber entablar diálogo con ese lenguaje para transformarlo en palabras de enseñanza, en palabras de vida para la comunidad. «No es fácil apoderarse de las palabras del padre creador y tampoco es fácil responderle» (Becerra, 1998, p. 17), y aquí lo que no es nada fácil lo atestigua la impresionante imagen poética del rayo surcando el cielo para contactar a un hombre con un propósito en su corazón, pues esa «energía» del rayo es la energía del rafue, con el cual los sabedores enseñan a los hombres, les aconsejan y les guían.

El aprender a escuchar las palabras es todo un ritual de iniciación en la sabiduría del rafue, a partir de la apertura de una ceremonia de la palabra, donde son transmitidos los saberes ancestrales: el komiuya jibibiri uai, el espacio pedagógico por antonomasia de esta cultura y el lugar donde se comparten los saberes interculturales. Inicia con la preparación del corazón (komeki) del aspirante al sabedor de las palabras de poder para hacer amanecer pensamientos guiados por el corazón, se cuida del pensamiento, así como se cuidan las palabras, ya que «la palabra es la parte vital en el hombre, por eso debe ser acatada. En realidad, la palabra verdadera nos llega en lo más profundo del corazón (komeki anamo)» (Becerra, 1998, p. 17). Es así como el aspirante a sabedor comunica el propósito para el cual quiere ser receptáculo de sabiduría. Así le habla a moo:

Yo necesito esa palabra de poder, esa palabra fuerte será transformada en buenas palabras, palabras con que enseñaré a mis hombres. A través de mí, las palabras fuertes serán palabras de conocimiento, de tranquilidad y de fortaleza. Con esta clase de lenguaje se recibe el poder que llega del Padre a través del rayo, y estas son las palabras que reciben y necesitan los grandes sabedores (Becerra, 1998, p. 17).

El rafue es transmitido oralmente desde el origen en las lenguas ancestrales. Aun cuando hoy en día se use la escritura para fomentar estas literaturas indígenas, la escritura no puede guardar el poder, la musicalidad y el sentido de la lengua original. El rafue prescinde de la escritura alfabética, a pesar de que las instituciones culturales y las editoriales poco a poco se han concientizado de la tarea de difundir un legado de

6. Nimairama: abuelo o sabedor que se reconoce por sus servicios de sanador y educador en las comunidades. 
conocimiento ignorado en su mayor parte por Occidente. A diferencia de la tradición literaria occidental en la que prevalece la escritura sobre la oralidad, en El poder de la palabra, difundido por Eudocio Becerra, se advierte que la poesía sigue siendo más primigenia que la escritura. La poesía antecede y trasciende las grafías. En palabras de Vivas:

La escritura de la poesía no puede ser relevante para comprender qué es la poesía [...], la poesía es más antigua y diversa que la invención de la escritura y sus técnicas de corrección y edición. Antes de la letra ya existía la poesía y, aún hoy, la poesía existe en sociedades ágrafas. Así que la poesía ancestral no tiene que ser escrita para ser poesía, pues lo que le da origen a la necesidad humana de la poesía son las preguntas fundamentales de la existencia en su búsqueda de la reconexión con la naturaleza (Vivas, 2015, p. 76).

Aun cuando la poesía ancestral ni sus filosofías se sustentan en la escritura, ya que entre los múrui-muina los rafuentai se han transmitido milenariamente a través de la palabra oral y, aún hoy, la palabra poética es el alimento (monifue) de cada día para los hablantes de la lengua minika. El rafue que es la palabra de poder, la que hace amanecer, ha sido transmitida en una extensa sucesión de generaciones que se apoyan en una multiplicidad de elaboraciones poéticas que reconocemos en los kitrigatai. La palabra escrita, sin embargo, no podría oponérsele, si bien «antes de la letra ya existía la poesía» (Vivas, 2015, p. 76), la palabra también ha amanecido en la literatura, por lo que cada vez hay más voces de abuelos que no saben escribir ni leer publicadas e impresas en libros y revistas, pero que nos dan cátedra en la lectura de la naturaleza, nos enseñan a leer el trueno, las hojas de coca o a cantar alegremente con el corazón triste. De esta manera, la palabra ancestral está amaneciendo en las nuevas generaciones, si de aquí o de allá, ya no importa, toda vez que la palabra se signa bajo la forma de rayo, se escucha en forma de trueno y nos llega en forma de viento.

\section{El rafue: un pensamiento original}

El pensamiento múrui-muina es un pensamiento que se siembra, se practica, se mambea y amanece en hechos reales, esta palabra adquiere la fuerza de concreción gracias al trabajo comunitario. El saber está vinculado con los espacios de compartir en comunidad en los que, entre otras cosas, se juega, se teje, se siembra, se cocina, se canta, se danza, etc. Así los espacios de aprendizaje de las palabras de crecimiento (komuiya uai), están estrechamente relacionados con los espacios de la práctica de esos 
mismos aprendizajes. Espacios tales como la chagra en la que se siembra los alimentos y las plantas usadas en el mambeo, el monte donde se caza y la casa comunitaria en la que se piensa la cotidianos son propicios para hacer amanecer las palabras, es decir, para poner en acción lo aprendido. Así pues:

[...] la palabra fuerte que es el rafue tiene un poder tal que impele a quien la sabe a ponerla en obra, en este sentido es eficaz. Claro está, su eficacia, plena sólo queda demostrada cuando se hace obra. Un rafue será propio rafue, como dicen los sabedores, si se concreta (Urbina, 2010, p. 104).

Lo mágico y lo poético de esta transformación de la palabra en obra, lo estético y lo filosófico de este pensamiento no le quita peso e importancia al trabajo manual de la siembra, la caza, la pesca y, en suma, a todas las labores cotidianas que hacen que las palabras amanezcan en obras. Por ende, las prácticas rituales y el pensamiento filosófico están directamente vinculados con los trabajos manuales y comunitarios de la cultura múrui-muina. Aprender del rafue, es aprender a escuchar a los ancestros que han cultivado la tierra, que siembran y cuidan las plantas, que protegen el territorio y armonizan las relaciones entre los hombres y la naturaleza. Sin embargo, transmitir el conocimiento cultivado milenariamente a las jóvenes generaciones es una labor exigente y muchas veces, descorazonadora, cuando:

[...] los jóvenes se avergüenzan de ser indígenas y no quieren aprender el saber de los antiguos y las palabras (rafue) de la coca, de la yuca y del tabaco, las palabras de la sal, palabras de abundancia, de dejar camino abierto, palabras de saber, palabras de enderezar rumbos, palabras de rechazar la enfermedad y convertir el sufrimiento en cosas buenas, palabras de hacer amanecer que nos dio el padre para vivir bien (Kuegagíma, citado por Urbina, 2010, p. 101).

En estas palabras del abuelo Félix Kuegagíma, del clan Nogonï, gente de olla, se constata que la compleja misión de transmitir los saberes milenarios, de humanizar, de sensibilizar y de celebrar la vida, también conlleva la difícil tarea de descolonizar el pensamiento. Las «nuevas generaciones» no quieren aprender de sus abuelos, de sus mayores, de sus taitas, y, en cambio, aprenden al dedillo los modelos colonizadores, las estructuras patronales del comercio y el progreso, el cálculo diferencial del racismo, las matemáticas imaginarias del narcotráfico; pero, así mismo, sueñan con ingresar a las universidades occidentales, donde se aprende a olvidar los propósitos culturales originario, así como las leyes y los principios del origen ancestral. Esto trae como consecuencia el desarraigo que esteriliza las propias culturas, el repudio por sus lenguas, 
el olvido de sus historias, el desprecio por la propia identidad y el abandono de sus territorios. En pocas palabras, constituye un peligrar de sus tradiciones milenarias.

Un problema tan complejo como el anteriormente mencionado lo viven los saberes ancestrales, cuando son interpretados desde las categorías de la ciencia, la filosofía, la lingüística y la antropología. Por ejemplo, se habla de fábulas, de cuentos, de relatos, de mitos o, simplemente, del folclor indígena. Y más aún, han sido seleccionados para integrar antologías de mitos y leyendas colombianos ignorando las lenguas originarias. El vocabulario bilingüe uitoto-español español- uitoto de los Minor traduce la palabra rafue como «el cuento, el asunto, la información, la fiesta» (1987, p. 97) y el diccionario incluido en el estudio de Preuss Mitología y religión de los uitotos lo toma como «el conjunto de todas las tradiciones: baile, fiesta, historias, enseñanzas» (Preuss, 1994, p. 887). El rafue se potencializa cuando deja de ser comprendido simplemente como un festejo o una parranda típica colombiana, pues pasa a tener una dimensión distinta, sin dejar de tener toda la categoría musical y poética en los cantos y en las danzas. De este modo, la palabra rafue no agota su sentido en el significado de fiesta, que si bien resulta acertada no se limita a este significado.

En Tabaco frío, coca dulce se presencia una «fiesta de la palabra», el cual es un gran trabajo literario cuyas cualidades más grandes son el de haber sido concebido como un diálogo, que deja habitar la música entre sus líneas, y el de transmitir la originalidad del pensamiento múrui-muina. El abuelo Hipólito Kinerai le devuelve al término rafue el significado de enseñanza y lo recrea en el komúiyafue ${ }^{7}$, la palabra de vida, «el sembrador de la verdadera semilla ( $U a$ iji ritimie)» hasta otorgarle un valor epistemológico con toda la profundidad filosófica que este concepto amerita. La sucesión de preguntas aquí son claves y todas desembocan en la pregunta por el conocimiento. Se interpela así al rafue: ¿de dónde viene? ¿quién lo trae? ¿quién lo entiende?, ¿cómo se aprende? ¿cómo se enseña? El concepto rafue termina siendo el centro de atención del primer yetárafue que presenta el libro. El orden es aquí fundamental, con esta palabra de consejo (yetárafue) se le da inicio al libro más logrado del pensamiento y la poesía de la cultura minika, escrito en su propia lengua y construido en base a la musicalidad de sus ritmos.

7. Komúiyafue o yetárafue son las dos denominaciones que Juan Álvaro Echeverri utiliza para nombrar las diferentes palabras de consejo en que se divide el libro Tabaco frío, coca dulce. La palabra komúiyafue contempla el komuide (germinación) y el rafue (palabra), así mismo el komúiyafue habla de «palabras de crecimiento». 
Ero kátmaki.

¿Buи mei úa ñuera rafue ari atidimie,

nï ráfuena onódimie,

nï rafue ua yorátma?

¿Nìi ráfuena onódimie,

nieze eróikana

onode?

¿Nieze eróikana ñúe rafue kioide

daidimie? (Candre \& Echeverri, 1993, p. 28; 2008, p. 22)

Mire nuestra gente.

¿Quién es el que trae la buena Palabra de vida

el que entiende esa Palabra

el que imparte esa Palabra?

El que entiende esa Palabra,

¿de qué manera

aprendió?

¿Cómo es la buena Palabra

y el que la ha llevado a cabo? (Candre \& Echeverri, 1993, p. 93; 2008, p. 25).

Estas palabras traídas del primer yetárafue seleccionado por Echeverri son de gran importancia filosófica, la cual radica en ser la primera vez que escuchamos una palabra de la lengua minika en la literatura occidental, que se interroga por el saber (onode). Y todavía más lo piensa en a partir de múltiples senderos, con una retahíla de preguntas:

¿Quién es el que trae la buena Palabra de vida

el que entiende esa Palabra,

el que imparte esa Palabra?

El que entiende esa Palabra, ¿de qué manera

aprendió?

¿Cómo es la buena Palabra

y el que la ha llevado a cabo? (Candre \& Echeverri, 1993, p. 93; 2008, p. 25).

Aquí se está ante la presencia de un pensamiento que se interroga tanto por el saber del rafue como por su pedagogía, de qué manera se aprende, de cómo se enseña. Este canasto de pensamiento es invaluable en la comprensión del pensamiento múrui-muina. En este trabajo se empezó por revisar el significado de la palabra rafue. Sin embargo, esta categoría epistemológica es disminuida cuando se va a ver tanto la traducción literal de los diccionarios como de las interpretaciones escuetas que la reducen a folklor o sabiduría popular. De ahí que algunos abuelos como Kinerai corrijan «una y otra vez» la incomprensión que se tiene de su sentido profundo:

8. La primera versión de Tabaco frío, coca dulce se publicó en 1993. La segunda versión está revisada y corregida. Esta se encuentra en formato PDF y apareció por primera vez en 2008. 
Kinerai se refiere una y otra vez a su Palabra (de la cual estos textos son una muestra) como rafue. Él aclara: «Esto no es Palabra de baile, pero es rafue; la gente cree que rafue es sólo baile, pero es porque no saben». En un baile se buscan cosas (comida) para alegrar a la gente, pero la Palabra de Kinerai es komúiyafue, es decir «Palabra de vida». Es una Palabra que busca el crecimiento de la gente - nuevas criaturas, nuevas generaciones. Una Palabra así no se «amanece» (no se manifiesta en Cosas) rápido, como la Palabra de baile (Candre \& Echeverri, 1993, p. 163).

El rafue que se transmite gracias a los canastos de conocimiento (kirigaiai) transmitidos por el abuelo Kinerai se refieren a un saber que da fuerza, que dota y revitaliza a los humanos tanto moral como espiritualmente. Cuando la palabra que se quiere hacer amanecer es una palabra de vida (komúiyafue), que quiere anunciar un pensamiento revitalizador, conlleva un trabajo más arduo, lo cual significa también que tardará más tiempo en madurar, pues se busca hacer amanecer el pensamiento ancestral en la nueva generación humana. Esa cualidad propia del rafue de hacer amanecer un pensamiento en la humanidad, de otorgarle una dirección, de germinar en el corazón de los hombres palabras dulces llenas de sabiduría es descrita por Urbina en Las palabras de origen:

[...] el rafue es una palabra ya purificada, referida a los actos culturales más decantados, más probados, repetidos, como son los que aluden al alimento cultivado y procesado, especialmente cocinado; aquel cuya ingestión va a permitir que el hombre sea humano en un mundo humanizado, mundo último, superación de los anteriores (Urbina, 2010, p. 107).

Esta palabra de vida (komuiya uai) que quiere amanecer a través de las palabras de poder no es nada que se refiera a ir a una parranda o andar de fiesta en fiesta. Esta ñuera komuiya uai o palabra de vida buena es el legado de una gran tradición que piensa la humanidad. Su proyecto de humanización es un portentoso proyecto cultural, y por eso la palabra que se quiere hacer amanecer es más lenta y difícil de aprender, pues es un proyecto de gran aliento. El rafue tiene una misión digna de un pueblo sabio: enseñar a las nuevas generaciones a escuchar el poder de las palabras.

\section{Conclusiones}

El rafue, como se acabó de ver, se manifiesta en múltiples producciones verbales de la tradición múrui-muina. De ahí su gran importancia a la hora de comprender el pensamiento ancestral de esta cultura. El término rafue no puede reducirse o traducirse 
meramente como «palabra» debido a la capacidad creativa, a la fuerza poética que «quiere hacer amanecer» (monaitaiakade) las obras culturales, artesanales, la abundancia de alimentos, el bienestar y la armonía con el territorio. Este concepto es de gran significado para la cultura minika en tanto da cuenta de una sabiduría milenaria que se manifiesta en acciones que benefician a la comunidad y se legitima el pensamiento ancestral como un saber pensar, un saber contar y un saber hacer amanecer la buena palabra. Por ello, la tradición múrui-muina es una cultura del amanecer. El término monaitaiakade que es transversal a las comunidades minika, bue, nipode, mika, okaina y nonuya, devela que estas culturas han sido engendradas por las mismas palabras de sabiduría, las cuales a su vez tienen múltiples convergencias en sus modos de nombrar y experimentar el mundo, pues se han alimentado de la sabiduría que propicia el contacto con sus territorios y sus lenguas, así como albergan las historias y las cartografías de sus lugares de origen.

Cuando las comunidades reconocen sus legados ancestrales, hablan sus lenguas, defienden sus ríos, cuidan sus selvas y sus bosques, practican sus saberes artesanales y rituales, la vida adquiere sentido. Las palabras amanecen en alimentos, en bienestar y en abundancia, por lo cual hay razones para celebrar con el canto y la danza. Celebrar la vida le concede al hombre la oportunidad de entrar en el goce estético, de aprender a vivir, a sentir, a ver y a saborear la vida. Los múrui-muina aprenden del rafue una ética del buen vivir, un modo de vida buena, tanto como una poética, aprendidos a través de los cantos, de las danzas y de los maravillosos relatos de origen. El poder de la palabra atraviesa a los hombres como el rayo, se manifiesta en el cuerpo a través de la danza y corrige los pasos de la comunidad en los movimientos espirales, circulares, solares y lunares. Penetra en todas las esferas sociales para invitar a los hombres, a las mujeres, a los niños y las niñas, a escuchar los sonidos primordiales de la tierra que vibra, habla y canta una música original que enseña a compartir y a vivir en comunidad. A través de la literatura múrui-muina se comprende que el rafue quiere hacer amanecer una enseñanza entre los suyos, en los otros y por «lo otro» que es la naturaleza. En suma, hacer amanecer un pensamiento cantado y celebrado en el corazón del todo. El rafue le canta a la vida y enseña a vivir, la fuerza poética del canto enseña a vivir en armonía a los seres humanos entre sí y con la naturaleza. 
El rafue es la palabra que piensa la cultura múrui-muina, pero este pensamiento se materializa al celebrar la vida a través del canto, de la danza y de la ceremonia. La danza le agrega un ritmo a la vida cotidiana de las comunidades indígenas, pues ellos danzan para caminar con pasos más armoniosos por los caminos de la tierra. Los cantos ritualizan la vida y agradecen la existencia de los frutos, de los alimentos, de las plantas, de los animales, de los bosques, de los saberes, etc. En suma, la palabra poética, el rafue, que piensa la vida, también cumple un papel central: educar a las nuevas generaciones en el respeto por la vida y a valorar los dones que vienen de la tierra. Esto es así porque el rafue es enseñanza, el rafue es poesía, es música y sabe danzar. El rafue nos enseña a penetrar en el pensamiento minika, como bien lo decíamos antes al citar a Bigidima, si queremos aprender del pensamiento ancestral hay una puerta abierta que es el rafue, palabra que enseña a escuchar, palabra que transforma, palabra de sanación, de liberación, canto que retorna a los tiempos de los ancestros, danza que nos recuerda que las raíces de nuestros pasos están sembradas en la Tierra.

\section{Referencias bibliográficas}

1. Becerra, E. (1998). «El poder de la palabra». En: Forma y función, 11, 15-28.

2. Becerra, E. (2003). Kat moo binie komuitajagai jiyaki: Relato de la creación de la tierra hecha por nuestro padre. Grupo de Investigación Transdisciplinaria Asterión, Universidad Nacional de Colombia. Bogotá, Ediciones Asterión.

3. Candre, H. (Kinerai) y Echeverri, J. (1993). Tabaco frío, coca dulce. Bogotá, Colcultura (Instituto Colombiano de Cultura).

4. Candre, H. (Kinerai) y Echeverri, J. (2008). Tabaco frío, coca dulce. Segunda edición. Recuperado de http://www.bdigital.unal.edu.co/2277/3/9789584445230.pdf

5. Fairinama, J. (2016). Jagagiai: Ríazéyue (y otros narradores minika). Medellín, GELCIL, Universidad de Antioquia.

6. Gasché, J. y Vela, N. (2012). Sociedad bosquesina. Lima, Perú. Instituto de investigaciones de la Amazonía peruana (IIAP), Iquitos.

7. Jitómagaro, J. «El lenguaje de la tierra». En: Agenda Cultural Alma Máter. Universidad de Antioquia, 175, abril 2011. 
8. Kuiru, J.; Jitoma, N.; Berrío, M. y Vivas, S. (2017). Jagagiai. Narraciones indígenas de la selva. Ediciones Norma. Bogotá.

9. Londoño, C. (2004). Muinane: Un proyecto moral a perpetuidad. Editorial Universidad de Antioquia.

10. Minor, E. \& Minor, D. (1987). Vocabulario bilingüe huitoto-español españolhuitoto. Lomalinda, Editorial Townsend.

11. Preuss, K. (1994). Religión y mitología de los uitotos. (Traducción y revisión de la transcripción de Gabriele Petersen de Piñeiros, Eudocio Becerra y Ricardo Castañeda Nieto). Bogotá, Editorial Universidad Nacional.

12. Trillos, M. (2003). Pasión y vida de las lenguas de Colombia. Bogotá, Colombia. Colciencias.

13. Urbina, F. (2003). Moniya Amena —El árbol de la abundancia-. Tablero, Revista del convenio Andrés Bello. 66, Bogotá.

14. Urbina, F. (2010). Las palabras del origen. Breve compendio de las mitologías de los uitotos. Bogotá: Ministerio de Cultura.

15. Urbina, F. (2003). El corazón del padre. Mito y rito del juego de pelota entre los uitotos. En: Racionalidad y discurso mítico. Bogotá: Universidad del Rosario, 2003.

16. Vivas, S. (2012). Kirigaiai: Los géneros poéticos de la cultura minika. Antípoda, 15, 225-244.

17. Vivas, S. (2015). Komuya uai, poética ancestral contemporánea. Medellín, Sílaba Editores, Editorial Universidad de Antioquia. 